\title{
Mediastinal cyst containing mural pancreatic tissue
}

\author{
M. J. T. CARR ${ }^{1}$, A. K. DEIRANIYA ${ }^{1}$, AND P. A. JUDD ${ }^{2}$ \\ From the Cardiothoracic Unit ${ }^{1}$, and Department of Pathology', Queen Elizabeth Hospital, Birmingham \\ B15 2 TH
}

Carr, M. J. T., Deiraniya, A. K., and Judd, P. A. (1977). Thorax, 32, 512-516. Mediastinal cyst containing mural pancreatic tissue. The second documented case of mediastinal ectopic tissue presenting as a mediastinal mass is reported. Previously reported cases of ectopic pancreatic tissue in the thorax are reviewed in an attempt to explain this anomalous development.

Mediastinal cysts are uncommon and only a minority of these are of enteric origin. The various types have been well documented previously (Fallon et al., 1954). A review of the English literature revealed that only one case of a mediastinal cyst containing predominantly pancreatic tissue has been described (Shillitoe and Wilson, 1957). This paper reports the second case of such a mediastinal cyst containing mural pancreatic tissue.

\section{Case report}

An asymptomatic 57-year-old woman was referred to the Cardiothoracic Unit at the Queen Elizabeth Hospital after the discovery on mass radiography of a large mass protruding into the left lung field.

On examination no abnormal physical signs could be elicited. Her haemoglobin, erythrocyte sedimentation rate, and white cell count were within normal limits. Similarly, her urea and electrolytes and blood glucose levels were unremarkable.

A chest radiograph showed a well defined mass, measuring $7 \times 6.5 \mathrm{~cm}$, with calcified borders, projecting into the left hemithorax and originating from the anterior mediastinum (Fig. 1a, b). A preoperative diagnosis of cystic teratoma was made. Surgical exploration and removal was advised.

A left sixth rib posterolateral thoracotomy was performed. A lobulated cystic mass, $10 \mathrm{~cm}$ in diameter with a smaller part lying superiorly, was found arising from the mediastinum. It was adherent to the overlying lung and was connected by a tenuous bridge of tissue to the thymus. The mass was peeled away from the lung with ease and the tenuous pedicle was ligated. The post- operative course was uneventful and blood glucose levels were within normal limits.

\section{PATHOLOGICAL FINDINGS}

The specimen consisted of an unopened, nearly spherical cyst, $10 \mathrm{~cm}$ in diameter, to which was adherent a smaller cyst measuring $1.5 \mathrm{~cm}$ in diameter. The larger cyst had a tough wall, ranging in thickness from 4 to $8 \mathrm{~mm}$, and it was filled with a pale brown fluid containing numerous small glistening particles which were probably cholesterol crystals. The smaller cyst was relatively thin-walled and it contained a brown pultaceous material.

Histological examination showed that the wall of the larger cyst was partly lined with a simple columnar epithelium (Fig. 2), but in many areas the epithelial lining was deficient and in its place there were collections of foamy macrophages. These cells were shown by Sudan stain and Perls' reaction to contain much neutral lipid and moderate amounts of ferric iron.

Within the thicker parts of the cyst wall there were several foci of pancreatic tissue, many of which closely resembled adult pancreas. The foci consisted predominantly of acinar exocrine tissue, but islets of Langerhans and epithelial lined ducts were also clearly seen (Fig. 3). As in the normal gland, the exocrine tissue was divided by fibrous septa into lobules, and most of the islets were found either within or at the periphery of these structures (Fig. 4). Intralobular and interlobular $\stackrel{?}{?}$ ducts were present and all but the smallest were $\square$ lined by columnar epithelium. The larger inter- $\bar{O}$

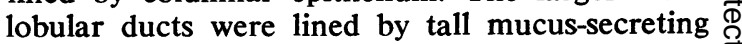
columnar cells, and small mucous glands were $\mathbb{D}$ present in the periductal tissue (Fig. 5). In some of 


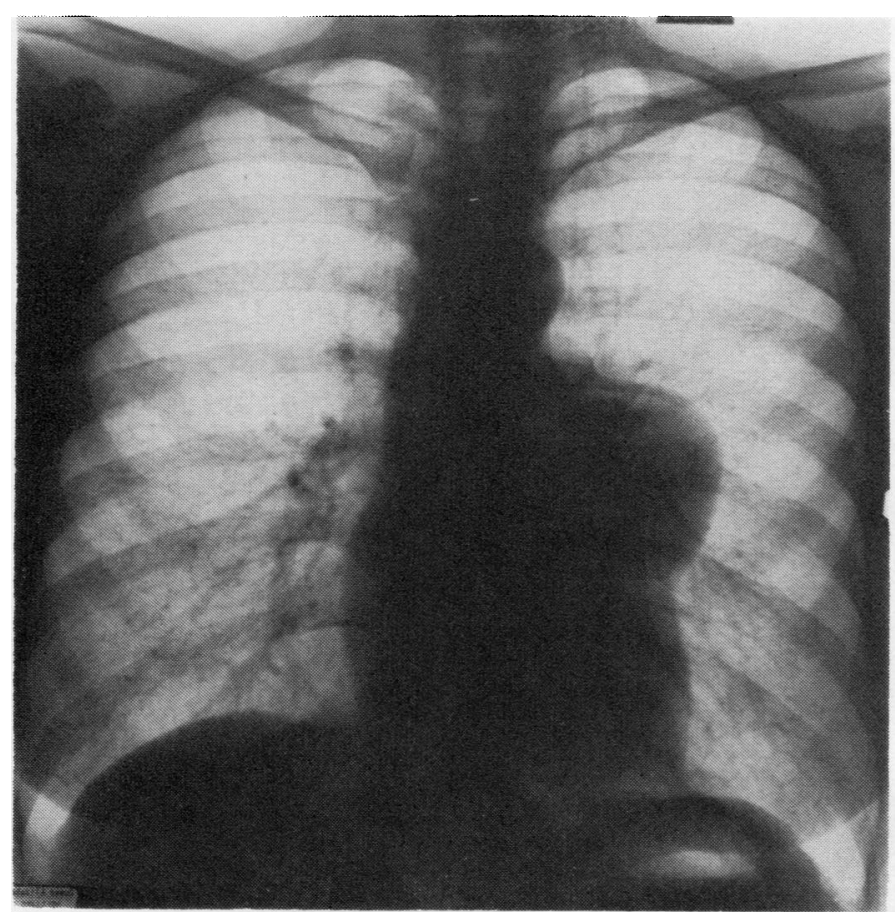

(a)

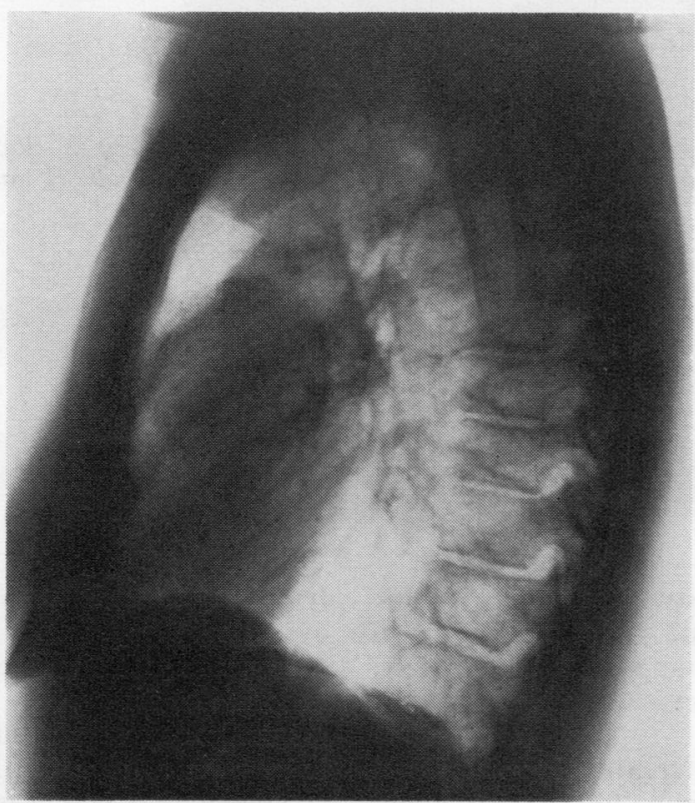

(b)

Fig. 1 Chest radiographs showing: (a) cyst with calcified wall projecting into the left hemithorax; and $(b)$ its anterior mediastinal location. 


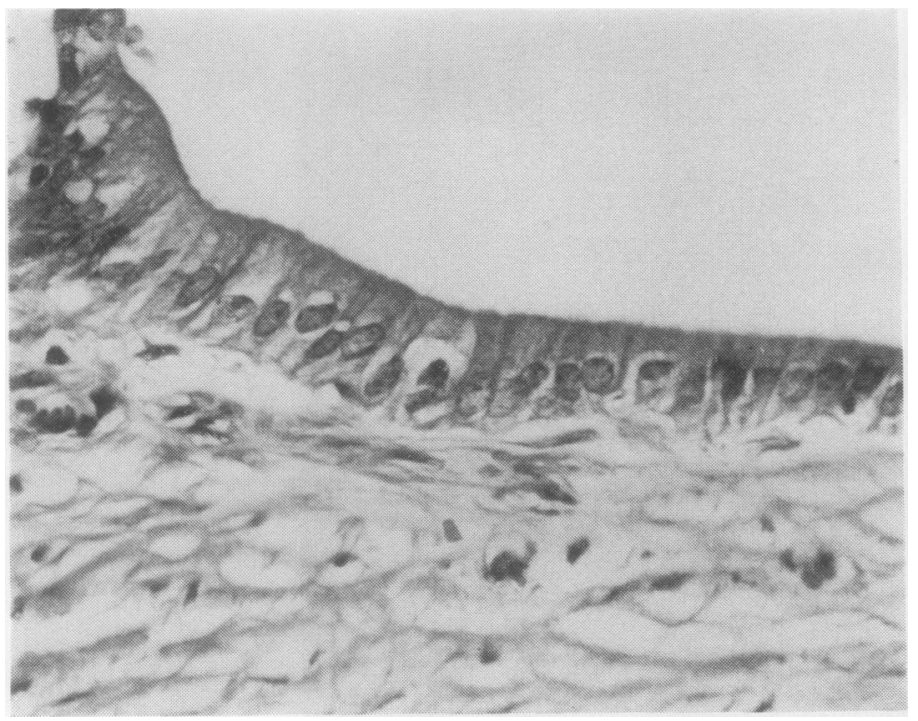

Fig. 2 Cyst wall lined with columnar epithelium. Haematoxylin and eosin $(H$ and $E) \times 160$.

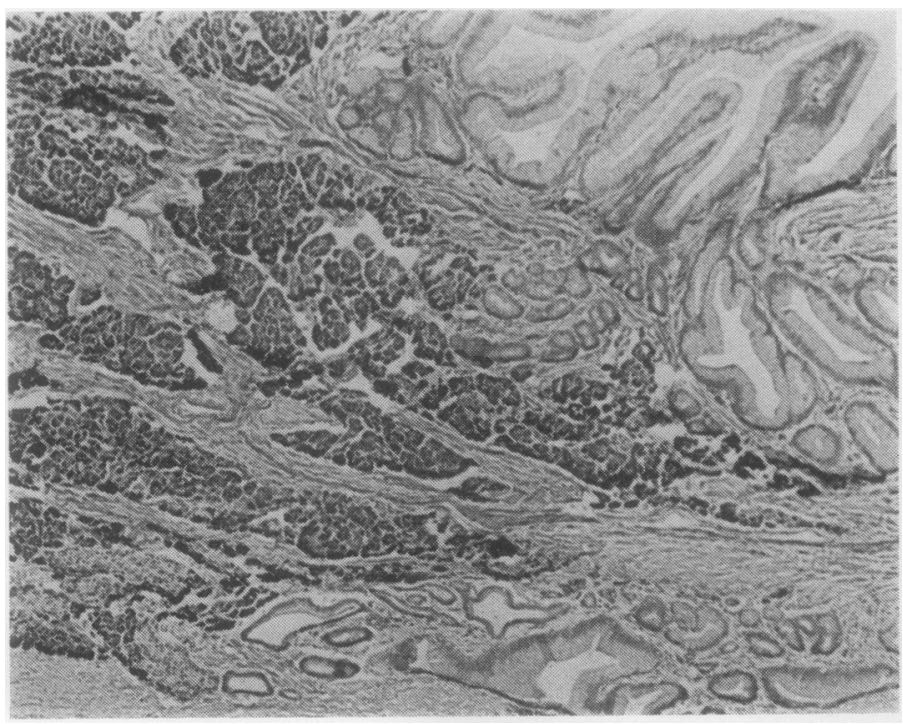

Fig. 3 Pancreatic tissue in the cyst wall. $H$ and $E \times 40$.

the smaller foci of pancreatic tissue the exocrine component showed atrophic features, and in a few instances it had disappeared completely, leaving a collection of islets and several simple ducts.

In regions devoid of pancreatic tissue the cyst wall consisted mainly of hyaline fibrous tissue containing small foci of dystrophic calcification. Other features present were several cholesterol granulomas (Fig. 6), thick walled arteries and veins, and a few nerve bundles. A few small lymphocytic foci were found on the surface of the $\tilde{O}$ cyst, and the presence within them of occasional groups of epithelial-like cells, which were arranged in whorls and were similar in appearance to Hassall's corpuscles, suggested that the cyst may have been adherent to the thymus.

The smaller cyst was lined entirely with foamy 0 macrophages interspersed with cholesterol clefts, $\stackrel{0}{\circ}$ and its wall of hyaline fibrous tissue contained no pancreatic tissue.

Twenty blocks were prepared from the surgical $\bar{\sigma}$ 


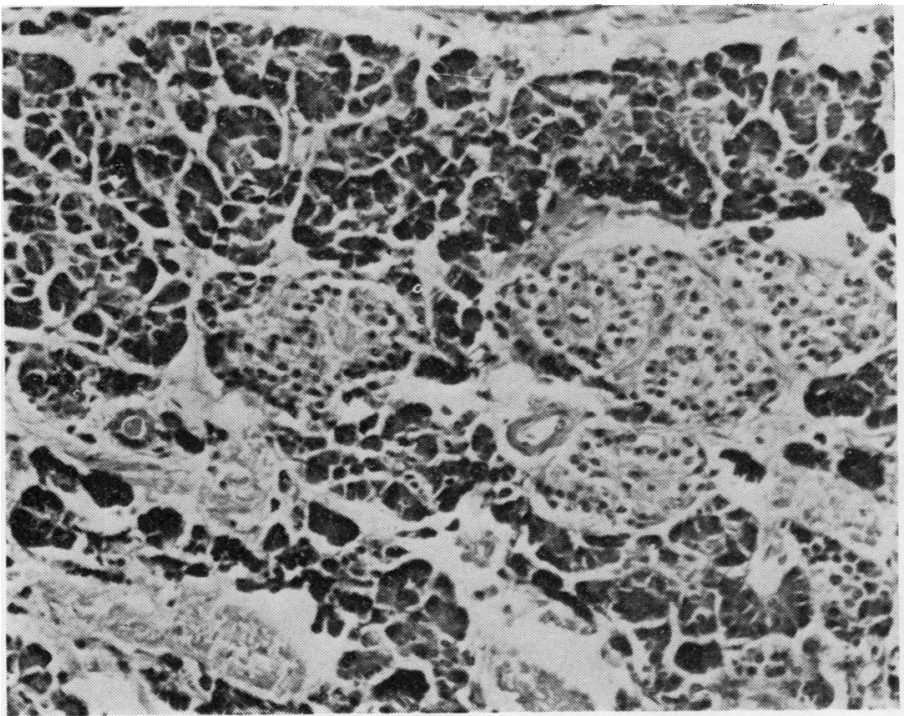

Fig. 4 Pancreatic tissue consisting of islets of Langerhans surrounded by exocrine glands. $H$ and $E \times 160$.

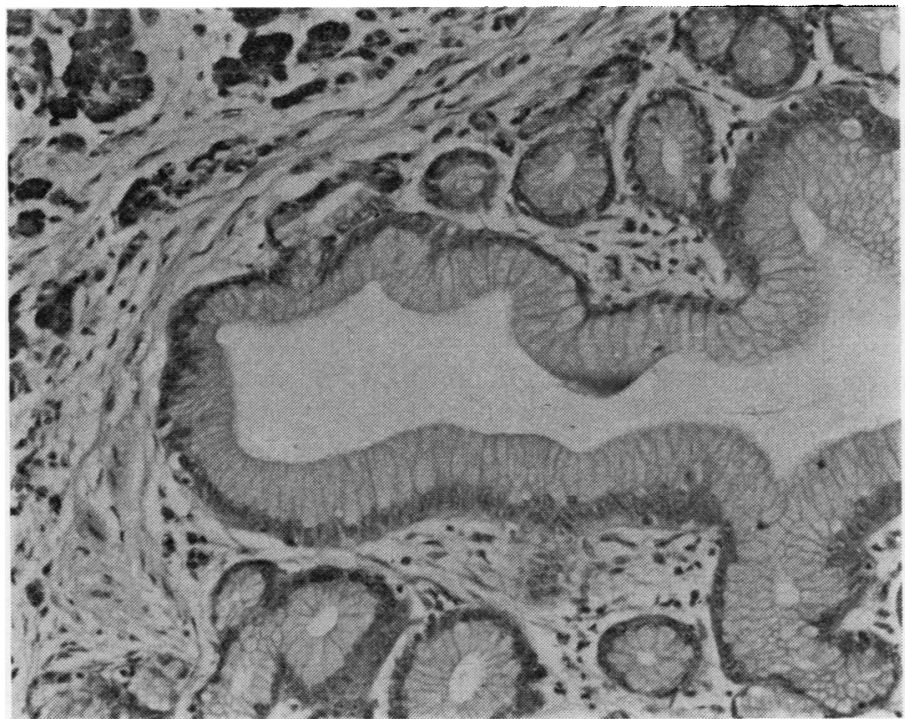

Fig. 5 A large pancreatic interlobular duct is lined with columnar epithelium. Mucous glands are present in the wall of the duct. $H$ and $E \times 160$.

specimen, but no tissue from any other part of the alimentary tract or from any other organ was found.

\section{Discussion}

The exact nature of this lesion is not absolutely certain; its position in the anterior mediastinum is against a gastroenteric origin since these lesions normally occur in the posterior mediastinum. In addition, these enteric cysts are often associated with abnormalities of the vertebral column, a feature not seen in this case.

On the rare occasions when pancreatic tissue is found in the mediastinum, it is usually a component of a mediastinal teratoma; the additional types of tissue which would constitute such a structure were not found in this specimen.

With the exception of the case described by Shillitoe and Wilson (1957), previous recordings of the presence of pancreatic tissue in the thorax have been examples of sequestrated lung which 


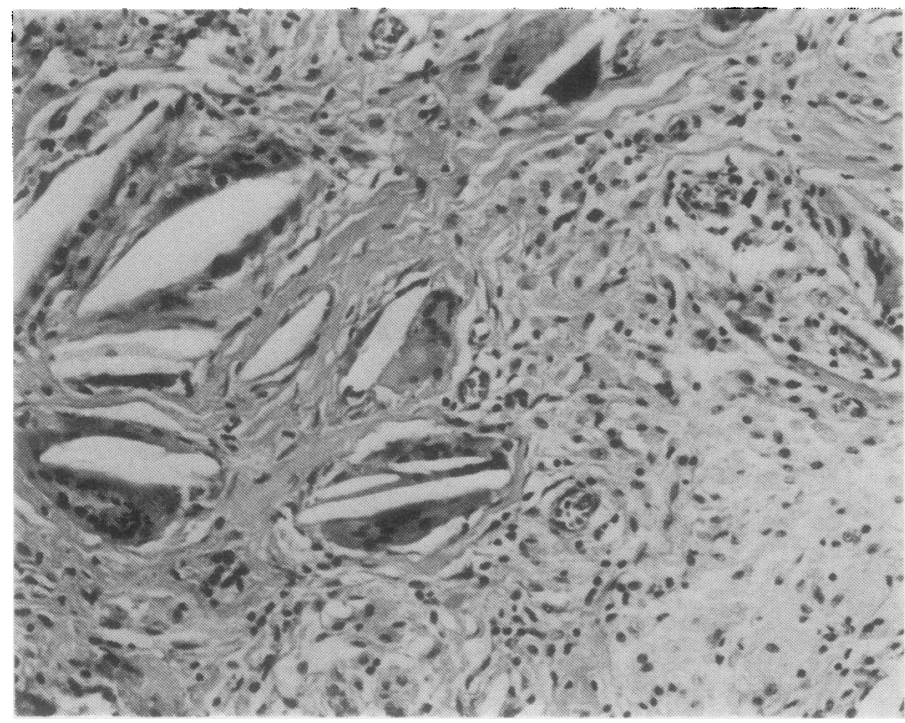

Fig. 6 Cholesterol granuloma consisting of foamy macrophages and foreign body giant cells containing cholesterol clefts. $H$ and $E \times 160$.

is generally accepted as an anomaly of foregut development. However, Kellett et al. (1962) interpreted the presence of heteroplastic pancreatic tissue in the lung as the aberrant development of pancreas from bronchial tissue. Similar cases have been described by Beskin (1961) and Baar and d'Abreu (1949) in which pancreatic tissue was found in a sequestrated cystic lung lobe which was connected to the oesophagus by an oesophageal duplication. Another similar case, probably due to anomalous foregut development, is described by Tilson and Touloukian (1972), in which a mass of ectopic pancreas in the lower mediastinum was connected to the stomach by a duct.

\section{Conclusion}

The described cyst probably resulted from anomalous foregut development and is of the same type of developmental abnormality as is found in extralobular sequestration.

It is unlikely that the pancreatic tissue within the cyst wall is the only organoid tissue remaining in a cystic mediastinal teratoma. It is also unlikely, on account of its location and absence of other alimentary tract tissue, that it is an example of the type of enteric cyst encountered in the posterior mediastinum.

\section{Re:erences}

Baar, H. S., and d'Abreu, A. L. (1949). Duplications of foregut; superior accessory lung (2 cases); $\bar{O}$ epiphrenic oesophageal diverticulum; intrapericardial teratoid tumour; and oesophageal cyst. $\stackrel{\perp}{\perp}$ British Journal of Surgery, 37, 220-230.

Beskin, C. A. (1961). Intralobar enteric sequestration of the lung containing aberrant pancreas. Journal of Thoracic and Cardiovascular Surgery, 41, 314317.

Fallon, M., Gordon, A. R. G., and Lendrum, A. C. (1954). Mediastinal cysts of foregut origin associated with vertebral abnormalities. British Journal of ?

Surgery, 41, 520-533.
Kellett, H. S., Lipphard, D., and Willis, R. A. (1962). Two unusual examples of heteroplasia in the lung. Journal of Pathology and Bacteriology, 94, 421-425.

Shillitoe, A. J., and Wilson, J. E. (1957). Enterogenous o cyst of thorax with pancreatic tissue as a constituent. Journal of Thoracic Surgery, 34, 810-814.

Tilson, M. D., and Touloukian, R. J. (1972). Mediastinal enteric sequestration with aberrant pancreas; $N$ a forme fruste of the intralobar sequestration. Annals of Surgery, 176, 669-671.

Requests for reprints to: A. K. Deiraniya, FRCS, Cardiothoracic Unit, Queen Elizabeth Hospital, Edgbaston, Birmingham B15 2TH. 